\title{
RESPUESTA A BAYÓN
}

as muchas páginas que Juan Carlos Bayón dedica a contestar mi nota de página
y media «El cuatrilema del consecuencialismo» están justificadas plenamente:
el análisis que hace acerca de cómo juega el concepto de causa en el marco de
teorías morales consecuencialistas y deontológicas es extraordinariamente agudo
e iluminador.

Adhiero plenamente a una de las tesis de Bayón: el deontologismo parece enfrentar problemas similares a los que yo señalé con referencia especial al consecuencialismo. Así lo adelanté en la segunda edición de Ética y derechos humanos ${ }^{1}$, cuando aclaré, después de presentar el cuatrilema, que éste parece aplicarse también a una ética deontológica: ésta necesariamente usa el concepto de causa en la mayoría de las descripciones de las acciones que califica como prohibidas o permitidas y así se enfrenta a las alternativas de depender de la moral positiva, de volverse circular, de incurrir en un regreso al infinito (lo que aquí reemplaza a la aceptación de presupuestos deontológicos por parte del consecuencialismo) o de usar un concepto de causa que lleva a implicaciones morales contraintuitivas.

Debo agregar que veo un inconveniente adicional al señalado por Bayón contra una de las salidas más obvias que podría tener el deontologismo frente a esta dificultad crítica: la de valorar a las acciones sobre la base no de los resultados causales tomados en cuenta por la descripción relevante sino de la intención del agente. No parece que las intenciones sean significativas para la valoración de las acciones si no es como reflejo de rasgos de carácter o disposiciones del agente. Por lo tanto, un sistema ético cuyos juicios básicos valoran a las acciones por las intenciones con que son realizadas, es un sistema moral que tiene como elementos primitivos las virtudes de carácter. Cuando ese sistema

${ }^{1}$ Buenos Aires, 1989, pág. 337. 
moral se aplica al campo político tiene implicaciones perfeccionistas, ya que no nos permite formular juicios sobre la corrección o incorrección de acciones, a los efectos de delimitar la coacción estatal, que no dependan de valoración del carácter moral de las personas ${ }^{2}$.

No creo, sin embargo, que el consecuencialismo escape tan fácilmente, como Bayón supone, del cuatrilema. En primer lugar, me parece -aunque tal vez esto sea una cuestión verbal que pondría el límite entre consecuencialismo y deontologismo en un punto distinto del continuo que Bayón traza con tanta sutileza. No parece plausible sostener que «en una genuina teoría moral deontológica... la violación de un derecho, aun en esas circunstancias [en que es el único medio de evitar la violación de otro derecho], no podría calificarse ni siquiera como permitida...» Una vez que se acepta que los derechos tienen un alcance amplio, al advertir que éstos pueden ser violados tanto por acción como por omisión, una posición semejante haría al deontologismo absolutamente inaplicable: permanentemente llevaría a situaciones en que tanto la acción A como su omisión $-A$ resultan prohibidas. Mi propuesta frente a estas situaciones de conflictos de derechos es que, una vez que se descartan diversas maneras de resolver o de disolver el conflicto, el principio de inviolabilidad de la persona prescribe el curso de acción que lo infringe en menor medida al implicar el sacrificio de un bien menor -tomando sólo en cuenta comparaciones entre pares de personas y sin prestar atención al número de gente que pueden sufrir el sacrificio de ese bien menor o beneficiarse con la preservación del bien de menor entidad. Sólo cuando los bienes en conflicto son de igual entidad (en términos del valor de autonomía) el principio de inviolabilidad de la persona se vuelve inaplicable, ya que cualquier comportamiento del agente lo infringe en igual grado, y entonces se aplica sin restricciones el principio de autonomía, que valora la maximización de la autonomía personal; tal maximización toma en cuenta, por supuesto, el número de personas que se benefician agregativamente con esa autonomía personal ${ }^{3}$.

Esto quiere decir que la posición que defiendo no es aditiva en un primer nivel del tratamiento de los conflictos de derechos. Entiendo, efectivamente, que tal rasgo es distintivo de una posición

${ }^{2}$ Ver estos problemas en op. cit., cap. X y en Los límites de la responsabilidad penal, Buenos Aires, 1980, cap. IV.

${ }^{3}$ Véase Ética y derechos humanos, citada, cap. VIII, pág. 313. 
deontologista. Es posible un consecuencialismo que adopte un tratamiento maximizador de la distribución: por ejemplo, si permite que la autonomía de ciertos individuos se restrinja a niveles más bajos que la de los demás para que la autonomía de un mayor número de otros miembros menos autónomos de la sociedad se expanda, disminuyéndose la diferencia con la autonomía de los miembros más autónomos de la misma sociedad (muchas revoluciones sociales cruentas se han hecho con este objetivo). Pero si el principio de distribución que se adopta no permite políticas de esa índole, creo entonces que la posición se confunde con una deontológica, puesto que desaparece las posibilidad de adicionar transpersonalmente el goce del bien en cuestión -aunque ese bien incluya una dimensión de distribución.

No me parece que una posición consecuencialista con una concepción del bien compleja y cuyos elementos están ordenados lexicográficamente, como la que defiende Bayón, evite los problemas de una ética tan exigente que lleva a borrar la diferencia entre obligación y supererogación moral. En primer lugar, el hecho de que una parte del bien sea lexicográficamente prioritaria sobre la otra no quiere decir que esta segunda sea opcional sino que el deber de satisfacerla sólo surge cuando se han satisfecho los deberes relacionados con la primera dimensión del bien. Claro está que Bayón replicaría que cuando esa primera dimensión está constituida por la autonomía, el deber de satisfacer otros aspectos del bien no surge si esa satisfacción puede afectar la autonomía del agente. Sin embargo, el problema de la sobre-exigibilidad se produce en relación a la misma dimensión de autonomía: la obligación de no restringir, por acción u omisión, y aun de promover la autonomía de los menos autónomos implica una enorme dedicación de tiempo, energía y recursos que amenaza con reducir la autonomía del agente a un nivel apenas superior a la de aquellos miembros menos autónomos. Esta dificultad -que muestra una tensión entre los rasgos de imparcialidad, autonomía y supremacía de una ética liberal ${ }^{4}$ - no es propia del consecuencialismo sino que afecta por igual a una ética deontológica igualitaria. La única sugerencia que puedo dar frente a este problema consiste en que se tome en cuenta que lo que debe distribuirse igualitariamente es autonomía personal y que, por lo tanto, no podemos llevar esa distribución tan lejos que terminemos distribuyendo una cosa diferente a tal autonomía de la personal ${ }^{5}$.

${ }^{4}$ Véase idem, cap. IV, pág. 185.

${ }^{5}$ Véase ibidem, cap. IV, pág. 192. 
Pero el punto crucial de la salida que Bayón propone frente al cuatrilema consiste en distinguir la eficacia causal, que sería lo único necesario para los juicios éticos de corrección o incorrección moral, de la selección de una acción como la causa de un cierto estado de cosas, que sólo sería necesaria para juicios ulteriores de imputación tendentes a responsabilizar al agente por su acción. Mientras la eficacia causal sería puramente fáctica, la selección de la causa a los fines de la imputación tendría así presupuestos normativos. Por lo tanto, el consecuencialismo se vería libre del cuatrilema, ya que sus juicios básicos de corrección o incorrección moral no presuponen pautas normativas, y sólo lo hacen los juicios de imputación moral que se pueden apoyar cómodamente en los juicios básicos del consecuencialismo.

Sin embargo, creo que esta salida del cuatrilema no es tal sino que implica caer en el cuarto de sus términos: el de usar un concepto de causa tan amplio que tiene consecuencias contra-intuitivas. En efecto, el concepto de causa usado para formular juicios de corrección o incorrección moral sería el de condición necesaria o el de condición suficiente (primero Bayón parece inclinarse por este último pero luego explícitamente abraza el primero), sin la restricción referida a las circunstancias normales del contexto. Aun tomando en cuenta que en este nivel de evaluación moral no estamos reprochando o responsabilizando a un agente, un concepto tan amplio de causa sería inservible para formular juicios de corrección o incorrección moral. Con un principio normativo consecuencialista que se apoye en el concepto de condición necesaria prácticamente todo comportamiento activo o pasivo que realizamos es potencialmente incorrecto, puesto que probablemente sin él se evitarían daños más o menos remotos a otros individuos (esto es obvio cuando consideramos que prácticamente todo lo que hacemos lo podríamos reemplazar por alguna acción de ayudar a alguien). También es probable, que esos daños se vean compensados por beneficios más o menos remotos. Pero dado que no hay límites a las cadenas de fenómenos sobre los cuales nuestras acciones y omisiones tienen «eficacia causal», lo cierto es que prácticamente nunca podríamos saber si una acción u omisión es correcta o incorrecta (aun un homicidio pudo haber impedido que la víctima, o algunos de sus descendientes potenciales, cometiera un genocidio en el tiempo de vida del que lo hemos privado). Si concebimos a la eficacia causal en términos de condición suficiente, la situación sería todavía peor, ya que sólo sería correcto o incorrecto el conjunto de condiciones que no se daría si no se hubiera dado el resultado, con lo que no habría posibilidad de discriminar a los 
efectos de esta evaluación moral entre el disparar al corazón de la víctima y el haberse movido inocentemente de una posición que se interponía en la trayectoria del disparo.

Los juicios objetivos de corrección o incorrección moral, si bien no sirven para reprochar al agente, puesto que no toman en cuenta sus intenciones y motivos, cumplen otras funciones en el discurso moral que no se satisfarían si se apoyaran en concepto tan amplio de eficacia causal. En primer lugar, son el presupuesto necesario de tales juicios de reproche: si la acción no es incorrecta no es posible reprochársela al agente y, además, para reprochársela al agente es generalmente necesario que él haya querido realizarla sabiendo que es incorrecta o al menos sabiendo que satisfacía la descripción que la hace incorrecta. Si bien puede parecer a primera vista que para todos estos efectos basta que la acción sea causalmente eficaz de un resultado prohibido o disvalioso, esto no es así: aun cuando, por ejemplo, al encender una luz que permite al asesino visualizar a su víctima y matarla, yo haya sabido y querido producir ese efecto, hay una importante diferencia en el valor moral objetivo de mi acción y la del asesino, y es a diferencia sólo se atenúa si yo había concertado ayudarlo de ese modo y mi acción de prender la luz no es, supongamos, la que hago regularmente a esa hora como funcionario encargado del alumbrado público. Esto quiere decir que el reproche no surge de juicios de incorrección moral basados en la mera eficacia causal de las acciones una vez combinados con juicios acerca de las intenciones y motivos del agente. El reproche requiere, además de la consideración de circunstancias subjetivas del agente, juicios de incorrección moral basados en una discriminación causal más fina que la mera condicionalidad suficiente o necesaria.

Por otra parte, los juicios de corrección o incorrección moral objetiva también son relevantes a otros efectos, como, por ejemplo, determinar cuándo es lícito que un tercero impida o promueva el comportamiento en cuestión ${ }^{6}$. También aquí si tales juicios se apoyaran en el mero concepto de eficacia causal se tornarían inservibles: es obvio que no es objetivamente legítimo impedir todas las condiciones necesarias de los resultados prohibidos o disvaliosos (piénsese en las infinitas condiciones que hicieron posible que Hitler desencadenara el Holocausto- por ejemplo, todos los innumerables hechos sin los cuales la concepción

\footnotetext{
${ }^{6}$ Véase este punto en Los límites de la responsabilidad penal, citada, cap. V.
} 
de Hitler por sus padres no se hubiera producido -y pregúntese si tiene sentido, a los fines prácticos de nuestro discurso moral, sostener que todas esas condiciones podrían ser legítimamente impedidas).

Por cierto que nada impide contar con un concepto de corrección o incorrección moral objetiva basado en la noción de eficacia causal. Creo, sin embargo, que ese concepto sería inoperante en el marco del discurso moral y que necesariamente debemos contar con otro que, sin tomar en cuenta las intenciones y motivos del agente que determinan su acción, la singularicen como el factor que no se habría dado si un resultado prohibido o disvalioso no se hubiera producido en las circunstancias debidas o esperables del contexto.

Claro está que esto nos coloca de nuevo frente al cuatrilema, sea que partamos de una posición consecuencialista o deontologista. Este que podríamos rebautizar como el cuatrilema fundamental de la ética crítica parece ser bastante resistente a intentos de superarlo, como los que ha desplegado lúcidamente Bayón en el artículo que comento. 